\title{
Health-related quality of life of patients with diagnosed type 2 diabetes in Felege Hiwot Referral Hospital, North West Ethiopia: a cross-sectional study
}

\author{
Kidist Reba ${ }^{1 *}$, Zeleke Argaw $^{2}$, Bizuayehu Walle $^{3}$ and Hordofa Gutema ${ }^{4}$
}

\begin{abstract}
Objective: Diabetes mellitus is a chronic non-communicable disease with considerable impact on health status and quality of life. It has a profound effect on quality of life in terms of social and psychological as well as physical well-being. This study was conducted to assess health related quality of life among patients with diagnosed type 2 diabetes.

Result: A cross-sectional study design was conducted from April to May, 2015. World Health Organization quality of life-BREF tool was used for collecting the data. A total of 344 patients with diagnosed type 2 diabetes were involved in the study. The overall health related quality of life mean score of the study participants was $52.6 \pm 12.1 \mathrm{SD}$. Social domain has higher mean score (57.8 \pm 14.8 SD). Educational status, marital status, occupation, duration of the diabetes and diabetes related complications had statistically significant association with health-related quality of life. An intervention that give special attention to the breaking of the cycle of low occupational status and literacy; and which encourage patients with type $2 \mathrm{DM}$ to have good control of their diabetes and prevent complication should be implemented to improve their quality of life.
\end{abstract}

Keywords: Health-related quality of life, Type 2 diabetes, WHOQOL-BREF

\section{Introduction}

Diabetes mellitus (DM) is defined as a chronic disease that occurs either when the pancreas fails to produce sufficient insulin which is type 1 diabetes or when the body cannot effectively use the produced insulin which is called type 2 diabetes. If it is not controlled, diabetes will result with hyperglycemia or raised blood sugar and over time leads to serious damage to the body's systems, particularly the nerves and blood vessels [1, 2].

Quality of life (QOL) is defined as individuals' perceptions of their position in life in the context of the culture and value systems in which they live and in relation to their goals, expectations, standards and concerns [3]. It is

\footnotetext{
*Correspondence: kidistreba@gmail.com

${ }^{1}$ Department of Adult Health Nursing, School of Health Science, College of Medicine and Health Science, Bahir Dar University, Bahir Dar, Ethiopia Full list of author information is available at the end of the article
}

a known fact that DM is associated with increased morbidity and mortality globally. However, its effect on functional health status and sense of wellbeing is still not well addressed, particularly in developing country where the prevalence is rising rapidly [2].

Different scholars have conducted study on QOL of patients diagnosed with diabetes and had reported that diabetes has a negative impact on HRQOL. However, since the tool used by these researchers to measure HRQOL was different among the studies and some of the studies have used small sample size, it is still arguable to know the correct finding about the QOL among patient with diagnosed type 2 diabetes [4-8]. Contrary to rapid increase of type 2 diabetes prevalence, studies conducted in developing countries are few in number and majority of them focused on both type of the diabetes, while those studies conducted on type 2 diabetes were done among 
patients who have experienced only specific DM complication $[4,6,9,10]$.

In Ethiopia, there is an increment in the trend of diabetes prevalence since 1980 with currently prevalence of $3.8 \%$. It also accounts $1 \%$ of total deaths of all age in the country. According to International Diabetes Federation (IDF), estimation, the 2.5 prevalence of diabetes in 2011 will rise to $3.5 \%$ by the year 2030 [2,11]. To combat the burden of this diabetes and other non-communicable disease (NCD), the country has implemented a national strategy based on the available evidence [12]. Since there is no study conducted on quality of life of patient with diagnosed DM to our knowledge, the current study will fill the existing gap in quality of life the patients.

Indeed, studies have been conducted on DM in Ethiopia. But, to our knowledge, all of them were undertaken to assess prevalence of DM and factors associated with it and there is no any study which conducted on HRQOL, specifically on type 2 diabetes [13-15]. Hence this study was conducted by aiming to assess HRQOL and its associated factors among type 2 diabetic patients on follow up in Felege Hiwot Referral Hospital (FHRH), North West Ethiopia.

\section{Main text}

\section{Study design and setting}

A cross-sectional study was employed from April 1 to May 15, 2015. The study was conducted among patients with diagnosed type 2 diabetes at FHRH which is found in Bahir Dar city. Bahir Dar city which is located on northwest and $565 \mathrm{~km}$ away from Addis Ababa; the capital of Ethiopia. FHRH is the only governmental hospital in the city. It has 200 beds and three medical OPD serves for medical patients of which one serve as referral and follow up clinic for patients with chronic diseases. Patients diagnosed with DM constitute larger number among patients attending in the follow up clinic.

\section{Sample size and Sampling}

Patients diagnosed with type 2 diabetes who had follow up for $\geq 1$ year, aged $>18$ years and visited the facility for follow up during the study period were selected and participated in this study after excluding patients who had history of substance abuse such as alcohol and cigarette.

\section{Sample size and sampling procedure}

Sample size was calculated using a single population proportion formula assuming proportion of HRQOL among 2 DM patients 50\%, 5\% margin of error (d) and $95 \%(\mathrm{z} \alpha / 2=1.96)$ and thus, the final sample size was calculated to be 384 .

A systematic sampling technique was employed to select study participants. After developing the sampling frame from the FHRH's follow up register, the sampling interval was calculated by dividing the number of individuals in the frame by the sample size.

\section{Data collection procedure}

Data was collected using interviewer administered structured questionnaire. The questionnaire adapted from validated instrument of WHOQOL-BREF tool [3]. The English version questionnaire was translated to Amharic (local language) and back translated to English by other person to check the consistence of the meaning. Four data collectors and one supervisor who are health professional were recruited.

\section{Instruments}

The instrument comprised of socio-demographic characteristics, DM related questions and the WHO-QOL tool. The WHOQOL-BREF is a 26-item instrument consisting of four domains: physical health (7 items), psychological health (6 items), social relationships (3 items), and environmental health (8 items), overall perception of QOL and general health (2 items). Each item of the WHOQOL-BREF is scored from 1 to 5 on a response scale, which is stipulated as a five-point ordinal scale. Three negatively worded items were reversely coded before attempt of any analysis. The score of each domain was obtained by summation of their corresponding items. The scores were then transformed linearly to a 0-100scale. Participants were weighed in $\mathrm{kg}$ in light clothing and bare feet. Height was measured using a measuring tape; participants stood in erect posture without shoes, and was recorded to the closer $0.5 \mathrm{~cm}$. Body mass index (BMI) was calculated as the ratio of weight in kilograms to the square of height in meters.

\section{Data analysis}

Data were entered into Epi-Data version 3.1 and exported to statistical package for social Sciences (SPSS) version 20 for analysis. All variables having a $p$ value of $\leq 0.2$ in the bivariate analysis were further entered in to multi variable regression. Backward step wise linear regression was performed. The result of the $\beta$-coefficient was used for interpretation of strength of prediction of the independent variables to the HRQOL. For all statistical significance tests, the cut- off value set was $\mathrm{p}<0.05$ at Confidence interval of $95 \%$.

\section{Results}

\section{Socio-demographic characteristics}

Making the response rate $90 \%$, a total of 344 patients with diagnosed type 2 diabetes were participated in the study. More than half $(57.3 \%)$ of the participant were male. The mean age of the participants was $40.5 \pm 15.2$ years. As of 
marital status, majority (60.8\%) of the participants were married. Regarding the educational status, 143 (41.6\%) of them completed secondary school and above (Table 1).

\section{Medical history and health condition}

As presented on Table 2, more than half (57\%) of the study participants were living with DM for less than 5 years and only 10 (2.9\%) of them living with it for more than 15 years. One third (64.3\%) of the participants are currently using insulin for the DM. Above half (53.5\%) of them have experienced DM complication. Of those who experienced DM complication, one fourth $(25 \%)$ of them have developed Diabetic retinopathy and 40 (21.7\%) of them experienced two or more complication. Regarding

Table 1 Socio-demographic characteristics of patients with diagnosed type 2 diabetes attending FHRH, North West Ethiopia 2015

\begin{tabular}{|c|c|c|}
\hline Variable & Frequency $(\mathrm{N})$ & Percentage (\%) \\
\hline \multicolumn{3}{|l|}{ Sex } \\
\hline Male & 197 & 57.3 \\
\hline Female & 147 & 42.7 \\
\hline Age (years) & $\begin{array}{l}\text { Mean and SD } \\
\quad(40.54 \pm 15.208)\end{array}$ & \\
\hline \multicolumn{3}{|l|}{ Educational status } \\
\hline Can't read and write & 117 & 34 \\
\hline $\begin{array}{l}\text { Read and write but no } \\
\text { formal educ. }\end{array}$ & 23 & 6.7 \\
\hline Primary education & 61 & 17.7 \\
\hline $\begin{array}{l}\text { Secondary education } \\
\text { and above }\end{array}$ & 143 & 41.6 \\
\hline \multicolumn{3}{|l|}{ Religion } \\
\hline Orthodox & 267 & 77.6 \\
\hline Muslim & 70 & 20.3 \\
\hline Protestant & 7 & 2.1 \\
\hline \multicolumn{3}{|l|}{ Ethnicity } \\
\hline Amhara & 336 & 97.6 \\
\hline Gurage & 4 & 1.2 \\
\hline Tigre & 4 & 1.2 \\
\hline \multicolumn{3}{|l|}{ Marital status } \\
\hline Single & 62 & 18 \\
\hline Married & 209 & 60.8 \\
\hline Divorced & 33 & 9.6 \\
\hline Widowed & 40 & 11.6 \\
\hline \multicolumn{3}{|l|}{ Occupation } \\
\hline Government employee & 104 & 30.2 \\
\hline Unemployed & 77 & 22.4 \\
\hline Merchant & 48 & 14.0 \\
\hline Student & 22 & 6.4 \\
\hline Farmer & 76 & 22.1 \\
\hline Private employee & 17 & 4.9 \\
\hline Monthly income (in birr) & $\begin{array}{l}\text { Mean and SD } \\
\quad(1962.6 \pm 6.5)\end{array}$ & \\
\hline
\end{tabular}

Table 2 Medical history and health condition of patients with diagnosed type 2 diabetes attending FHRH, North West Ethiopia 2015

\begin{tabular}{lcc}
\hline Variable & Frequency (N) & Percent (\%) \\
\hline Duration of DM (years) & & \\
$\leq 5$ & 196 & 57 \\
$6-10$ & 71 & 20.9 \\
$11-15$ & 66 & 19.2 \\
$>15$ & 10 & 2.9 \\
Drug regimen & & \\
Oral anti DM medication & 74 & 21.5 \\
Insulin & 221 & 64.3 \\
Insulin and oral anti DM medication & 49 & 14.2 \\
Presence of diabetes complication & & \\
Yes & 184 & 53.5 \\
No & 160 & 46.5 \\
Type of complication ( $\mathrm{n}=184)$ & & \\
Diabetic nephropathy & 21 & 11.4 \\
Diabetic neuropathy & 14 & 7.6 \\
Diabetic retinopathy & 47 & 25.6 \\
Diabetic foot ulcer & 39 & 21.2 \\
Diabetic related heart disease & 23 & 12.5 \\
Two and above complication & 40 & 21.7 \\
Body mass index (kg/m ${ }^{2}$ ) & & 5.1 \\
<18.5 & 16 & 4.7 \\
18.5-25 & 202 & \\
25-30 & 105 & \\
$>$ 30 & 21 & \\
\hline
\end{tabular}

the body mass index, majority (58.7\%) of them found in normal range (18.5-25) of BMI (Table 2).

\section{Factors associated with overall HROOL}

As presented in Table 3, Patients with diagnosed type 2 diabetes who are able to read and write and completed secondary school and above have 5.16 and 7.3 more HRQOL score than those who can't read and write $(\beta=5.16, p$-value $=0.019]$ and $(\beta=7.3, p$-value $=0.000)$ respectively. Patients who are divorced and widowed have -7.35 and -4.65 less HRQOL score than patients who are single $(\beta=-7.35, p$-value $=0.001)$ and $(\beta=-4.65$, $\mathrm{p}$-value $=0.033)$ respectively. Merchant and private employee patients who are living with diagnosed type 2 DM have 5.1 and 7.6 more HRQOL score than government employee $(\beta=5.09$, $p$-value $=0.003)$ and $(\beta=7.60$, $\mathrm{p}$-value $=0.007)$ respectively, while unemployed patients have -4.5 less HRQOL score than government employee patients $(\beta=-4.05$, $p$-value $=0.015)$.

Patients who are living with diagnosed type 2 diabetes for $6-10$ and $11-15$ years have -4.1 and -6.48 less HRQOL score than those who are living with it 
Table 3 Factors associated with overall HRQOL among patients with diagnosed type 2 diabetes attending FHRH, North West Ethiopia, 2015

\begin{tabular}{|c|c|c|c|c|}
\hline \multirow[t]{3}{*}{ Variables } & \multirow[t]{3}{*}{ Beta } & \multicolumn{3}{|c|}{ Overall HRQOL } \\
\hline & & \multirow[t]{2}{*}{$\mathrm{p}$} & \multicolumn{2}{|l|}{$95 \% \mathrm{Cl}$} \\
\hline & & & Lower & Upper \\
\hline Age & -0.03 & 0.536 & -0.12 & 0.06 \\
\hline Income (in Birr) & 0.0 & 0.683 & -0.001 & 0.00 \\
\hline \multicolumn{5}{|l|}{ Educational status } \\
\hline Can't read and write & 1 & 1 & 1 & 1 \\
\hline Read and write & 5.16 & $0.019^{*}$ & 0.85 & 9.46 \\
\hline Primary school & 0.52 & 0.758 & -2.78 & 3.84 \\
\hline Secondary school and above & 7.3 & $0.000^{*}$ & 4.00 & 10.62 \\
\hline \multicolumn{5}{|l|}{ Marital status } \\
\hline Single & 1 & 1 & 1 & \\
\hline Married & 2.01 & 0.195 & -1.03 & 5.05 \\
\hline Divorced & -7.35 & $0.001^{*}$ & -11.64 & -3.06 \\
\hline Widowed & -4.65 & $0.033^{*}$ & -8.94 & -0.37 \\
\hline \multicolumn{5}{|l|}{ Occupation } \\
\hline Government employee & 1 & 1 & 1 & 1 \\
\hline Unemployed & -4.05 & $0.015^{*}$ & -7.32 & -0.78 \\
\hline Merchant & 5.09 & $0.003^{*}$ & 1.71 & 8.47 \\
\hline Student & -1.20 & 0.636 & -6.19 & 3.79 \\
\hline Farmer & 1.25 & 0.493 & -4.83 & 2.33 \\
\hline Private employee & 7.60 & $0.007^{*}$ & 2.05 & 13.13 \\
\hline \multicolumn{5}{|l|}{ Duration of DM (years) } \\
\hline$\leq 5$ & 1 & 1 & 1 & 1 \\
\hline $6-10$ & -4.09 & $0.009^{*}$ & -7.14 & -1.05 \\
\hline $11-15$ & -6.48 & $0.000^{*}$ & -9.40 & -3.55 \\
\hline$>15$ & 2.41 & 0.478 & -4.27 & 9.01 \\
\hline \multicolumn{5}{|l|}{ Drug regimen } \\
\hline Oral anti DM medication & 1 & 1 & 1 & 1 \\
\hline Insulin & -1.73 & 0.226 & -4.53 & 1.07 \\
\hline Insulin and oral DM medication & -2.38 & 0.194 & -5.96 & 1.22 \\
\hline \multicolumn{5}{|l|}{ DM complication } \\
\hline No & 1 & 1 & 1 & 1 \\
\hline Yes & -4.82 & $0.000^{*}$ & -7.23 & -2.42 \\
\hline \multicolumn{5}{|l|}{ Body mass index (kg/m²) } \\
\hline$<18.5$ & 1 & 1 & 1 & 1 \\
\hline $18.5-25$ & -0.47 & 0.86 & -5.77 & 4.83 \\
\hline $25-30$ & -1.34 & 0.63 & -6.80 & 4.13 \\
\hline$>30$ & -5.78 & 0.85 & -12.41 & 0.81 \\
\hline
\end{tabular}

* Significant at $p<0.05$

for 5 years and below $(\beta=-4.09, p$-value $=0.009)$ and $(\beta=-6.48, p$-value $=0.000)$ respectively. Patients who experienced any of DM complication have -4.82 less HRQOL score than those who didn't develop any DM complication $(\beta=-4.82$, $\mathrm{p}$-value $=0.000)($ Table 3$)$.

\section{Discussion}

The current study demonstrated the HRQOL of patients living with diagnosed type 2 diabetes and attending DM follow up clinic in FHRH. In this study, we are able to identify $52.6 \pm 12.1$ mean score of the overall HRQOL among patient with diagnosed type 2 diabetes. This finding is comparable with the previous studies which used the WHOQOL-BREF scale to determine HRQOL of patients with DM. In studies conducted in Iran and Canada, the mean score of overall QOL was 51.2 and 54.7 in patient with diagnosed type 2 diabetes $[14,15]$. However, this finding is lower than that of study among Emirate people with DM which showed 63.1 mean score of overall HRQOL [16].

Among the four domains of HRQOL, study participants had the higher mean score (57.8) on social domains and lower mean score (48.1) in physical domain. Although they have different figure, this highest mean score in social domain was also reported in study among Iranian, Nigerian, Kenyan, Mexican, refugee in Gaza and Emirate people with DM [9, 14, 16-19]. Individual with type $2 \mathrm{DM}$ who are able to read and write, completed high school and above have better HRQOL than those who have no education. The finding of the studies conducted in Iran and Mexico on QOL also showed that HRQOL is significantly associated with educational status of patients with type $2 \mathrm{DM}[8,16,20]$, implying that patients with type $2 \mathrm{DM}$ who have higher educational status have better ability to make decision on self-care, better understanding about the disease, its complication and treatment.

Divorced and widowed patients with type 2 DM have lower QOL than those who are single. This relationship between marital status and QOL is also observed in previous studies conducted on DM patients $[8,16,18$, 19]. HRQOL of unemployed patients with type $2 \mathrm{DM}$ is lower as compared with those patients who are government employee, private employee and merchants. A national survey conducted in Iran has also reported significant association between employment and HRQOL of patients with type 2 DM [8]. A study done in Nigeria on QOL of patients with DM has also showed significant association of occupation with QOL [6].

Patients who are living with type $2 \mathrm{DM}$ for more than 5 years have worse HRQOL as compared with those who live with it for 5 years and less. This negative relationship between QOL and duration of DM is demonstrated in previous studies. In study conducted among Iranian and Emirates patients with diabetes has also shown the influence that duration of DM has on the QOL of patients $[8,18]$. The current study has also observed significant association between complication of DM and HRQOL of patients. It has demonstrated that patients with type 
2 DM who have developed any DM complication have worse QOL. The negative effect of DM complication on HRQOL of patients with DM has been reported in previous studies $[5,6,18]$.

\section{Conclusion}

The finding of the current study showed low mean score of overall and domain of HRQOL. The HRQOL of patients diagnosed with type $2 \mathrm{DM}$ is affected by their educational status, marital status, occupation, duration of DM and presence of DM complication. An intervention that give special attention to breaking the cycle of low occupational status and literacy should be implemented to improve the quality of life of DM patients. Moreover, it could direct researchers to understand how each domain of HRQOL are being affected.

\section{Limitations}

The limitations of the present study are; (1) the utilization of cross-sectional design; which lack reporting of causal relationship of the variables. (2) It has to be noted that the data was collected using interviewer administered questionnaire which may make the finding prone to social desirability bias.

\section{Abbreviations}

BMI: body mass index; DM: diabetes mellitus; FHRH: Felege Hiwot Referral Hospital; FMOH: Federal Ministry of Health; HRQOL: health related quality of life; IDF: International Diabetic Federation; NCD: non-communicable disease; OPD: out patient department; QOL: quality of life; SD: standard deviation; SPSS: statistical package for social sciences; WHO: World Health Organization; WHOQOL: World Health Organization quality of life.

\section{Authors' contributions}

KR conceived and designed the study. KR, BW, ZA and HG involved in data collection and analysis and interpretation. KR, BW and $\mathrm{HG}$ drafted the manuscript. BW, ZA and HG critically reviewed the manuscript. All authors read and approved the final manuscript.

\section{Author details \\ ${ }^{1}$ Department of Adult Health Nursing, School of Health Science, College of Medicine and Health Science, Bahir Dar University, Bahir Dar, Ethiopia. ${ }^{2}$ Col- lege of Medicine, Addis Ababa University, Addis Ababa, Ethiopia. ${ }^{3}$ Depart- ment of Physiology, School of Medicine, College of Medicine and Health Science, Bahir Dar University, Bahir Dar, Ethiopia. ${ }^{4}$ Department of Health Pro- motion and Behavioral Sciences, School of Public Health, College of Medicine and Health Science, Bahir Dar University, Bahir Dar, Ethiopia.}

\section{Acknowledgements}

We are grateful to the study participants for their time to participate in this study.

\section{Competing interests}

The authors declare that they have no competing interests.

\section{Availability of data and materials}

The datasets used and analysed during the current study are available from the corresponding author on reasonable request.

\section{Consent for publication}

Not applicable.

\section{Ethics approval and consent to participate}

Ethical clearance was obtained from Ethical clearance committee of Addis Ababa University. Written informed consent was obtained from all the study participants. Information obtained at any course of study was kept confidential. Patients who were found to have DM complications were counseled about the available treatment options and their advantages/side effects.

\section{Funding}

Addis Ababa University is the funding organization for the collection, entry, analysis and interpretation of this research data.

\section{Publisher's Note}

Springer Nature remains neutral with regard to jurisdictional claims in published maps and institutional affiliations.

Received: 6 June 2018 Accepted: 20 July 2018

Published online: 02 August 2018

\section{References}

1. WHO. Diabetes fact sheet. WHO; 2015. http://www.who.int/mediacentre/ factsheets/fs312/en/.

2. Shaw J, Sicree R, Zimmet PZ. Global estimates of the prevalence of diabetes for 2010 and 2030. Diab Res Clin Pract. 2010;87:4-14.

3. The WHOQOL Group. WHOQOL-BREF introduction, administration, scoring and generic version of the assessment programme on mental health. Geneva:WHO; 1996.

4. Abdelgadir M, Shebeika W, Eltom M, Berne C, Wikblad K. Health related quality of life and sense of coherence in Sudanese diabetic subjects with lower limb amputation. Tohoku J Exp Med. 2009;217(1):45-50.

5. Akinci F, Yildirim A, Gozu H, Sargin H, Orbay E, Sargin M. Assessment of health-related quality of life (HRQOL) of patients with type 2 diabetes in Turkey. Diab Res Clin Pract. 2008;79(1):117-23.

6. Issa B, Baiyewu O. Quality of life of patients with diabetes mellitus in a Nigerian teaching hospital. Hong Kong J Psychiatry. 2006;26:27-33.

7. Graham JE, Stoebner-May DG, Ostir GV, Snih SA, Peek M, Markides K, et al. Health related quality of life in older Mexican Americans with diabetes: a cross-sectional study. Health Qual Life Outcomes. 2007;5(39):1-7.

8. Javanbakht M, Abolhasani F, Mashayekhi A, Baradaran HR, Jahangiri Noudeh Y. Health related quality of life in patients with type 2 diabetes mellitus in Iran: a national survey. PLoS ONE. 2012;7(8):1-9.

9. Genga EK, Otieno CF, Ogola EN, Maritim MC. Assessment of the perceived quality of life of non insulin dependent diabetic patients attending the diabetes clinic in Kenyatta National Hospital. IOSR J Pharm. 2014;4(3):15-21.

10. Jain V, Shivkumar S, Gupta O. Health-related quality of life (Hr-Qol) in patients with type 2 diabetes mellitus. N Am J Med Sci. 2014;6(2):96-101.

11. WHO. Non-communicable Disease (NCD) Country profile. WHO; 2014. http://www.who.int/nmh/countries/eth_en.pdf.

12. $\mathrm{FMOH}$. National strategic action plan (NSAP) for prevention and control of non-communicable disease in Ethiopia. 2014-2016. Addis Ababa: $\mathrm{FMOH} ; 2014$

13. Ambachew $Y$, Kahsay $S$, Tesfay $R$, Tesfahun $L$, Amare $H$, Gebreegzihabiher $\mathrm{G}$, et al. Prevalence of diabetes mellitus among patients visiting medical outpatient department of Ayder referral hospital, Mekelle, Ethiopia: a 3 years pooled data. IJPSR. 2015;6(2):435-9.

14. Alemu F. Prevalence of diabetes mellitus disease and its association with level of education among adult patients attending at Dilla Referral Hospital, Ethiopia. J Diab Metab. 2015;6(4):1-5.

15. Abebe SM, Berhane Y, Worku A, Assefa A. Diabetes mellitus in North West Ethiopia: a community based study. BMC Public Health. 2014;14(97):1-8.

16. Gholami A, Azini M, Borji A, Shirazi F, Sharafi Z, Zarei E. Quality of life in patients with type 2 diabetes: application of WHOQOL-BREF Scale. Shiraz E Med J. 2013;14(3):162-71. 
17. Imayama I, Plotnikoff RC, Courneya KS, Johnson JA. Determinants of quality of life in adults with type 1 and type 2 diabetes. Health Qual Life Outcomes. 2011:9(115):1-9.

18. Bani-Issa W. Evaluation of the health-related quality of life of Emirati people with diabetes: integration of sociodemographic and disease-related variables. East Mediterr Health J. 2011;17(11):825-30.

19. Eljedi A, Mikolajczyk RT, Kraemer A, Laaser U. Health-related quality of life in diabetic patients and controls without diabetes in refugee camps in the Gaza strip: a cross-sectional study. BMC Public Health. 2006;6(268):1-7.

20. Martinez YV, Prado-Aguilar CA, Rascon-Pacheco RA, Valdivia-Martinez J. Quality of life associated with treatment adherence in patients with type 2 diabetes: a cross-sectional study. BMC Health Ser Res. 2008;8(164):1-10.
Ready to submit your research? Choose BMC and benefit from:

- fast, convenient online submission

- thorough peer review by experienced researchers in your field

- rapid publication on acceptance

- support for research data, including large and complex data types

- gold Open Access which fosters wider collaboration and increased citations

- maximum visibility for your research: over $100 \mathrm{M}$ website views per year

At BMC, research is always in progress.

Learn more biomedcentral.com/submissions 